\title{
Fertility desire and associated factors among HIV-positive women attending ART clinics in Afar region, Northeast Ethiopia
}

\author{
Etsay Woldu Anbesu ${ }^{1}$, Aydahis Ali Mohammed ${ }^{2}$ \\ ${ }^{1}$ Department of Public Health, College of Medical and Health Sciences, Samara University, Afar, Ethiopia \\ ${ }^{2}$ Afar Regional Health Bureau, Afar, Ethiopia
}

\begin{abstract}
Introduction: Human immune deficiency virus (HIV)-infected individuals experience significant implications in terms of having children due to transmission of human immune deficiency. However, fertility desire has given little attention, and the uptake of prevention of mother-to-child transmission services is low in Ethiopia, particularly in Afar region. Thus, this study aimed to assess fertility desire and associated factors among human immune virus-positive women attending ART clinics.

Material and methods: An institution-based cross-sectional study was conducted with $402 \mathrm{HIV}$-positive women attending anti-retroviral therapy clinics in selected hospitals of Afar region. Logistic regression analysis was employed to identify factors associated with fertility desire. Statistical association was measured, with a p-value $<0.05$ considered statistically significant.

Results: The prevalence of fertility desire was 63.9\% (95\% CI: 59.1-68.8\%). Young ages women, i.e., 15-24 years $(\mathrm{AOR}=11.98$; 95\% CI: 4.04-35.5) and 25-34 years $(\mathrm{AOR}=2.93,95 \% \mathrm{CI}: 1.46-5.86)$, who did not have living children ( $\mathrm{AOR}=5.1 ; 95 \% \mathrm{CI}: 1.31-20.2)$ and women with 1 or 2 children alive ( $\mathrm{AOR}=2.7$; 95\% CI: 1.39-5.27), and disclosed sero-status (AOR = 5.89; 95\% CI: 2.33-14.9) were associated with increased odds of fertility desire. However, contraceptives use was associated with decreased odds of fertility desire ( $\mathrm{AOR}=0.11 ; 95 \% \mathrm{CI}$ : 0.05-0.22).

Conclusions: In this study, six in ten study subjects had fertility desires. Young age, not having living child, having 1 or 2 children alive, disclosing sero-status to partner, and contraceptive use were predictors for fertility desire.
\end{abstract}

HIV AIDS Rev 2021; 20, 4: 281-286 DOI: https://doi.org/10.5114/hivar.2021.111395

Key words: prevalence, fertility desire, hospitals, Afar region, Ethiopia.

\section{Introduction}

Fertility desire is the intention to have children in the fertile ages from 15-49 years [1]. Human immune virus (HIV) is the virus that causes acquired immunodeficiency syndrome (AIDS), which is one of the world's most public health problems and challenges [2]. A high number of new HIV infections in children occur among children born to HIV-positive

mothers. People living with HIV (PLHIV), as the general population, might desire to have children [1].

Globally, more than 34 million people living with HIV, and nearly 30 million people have died from AIDS-related causes, since the beginning of epidemic [3]. An estimated $75 \%$ of all HIV-positive individuals were of reproductive age. Moreover, sub-Saharan Africa accounts for $60 \%$ of all people living with HIV/AIDS, out of which, more than half of these

Article history:

Received: 18.03.2021

Received in revised form: 04.05 .2021

Accepted: 05.05.2021

Available online: 30.11 .2021
International Journal of HIV-Related Problems

HIV \& AIDS $R$ e vi e w 
are females [4]. In Ethiopia, HIV prevalence among women of the reproductive age group (15-49 years) was 0.9\% [5].

Studies in several settings showed different factors, which determine fertility desire of HIV-positive women. Young age, HIV disclosures, perceived health status, and CD4+ count of more than or equal to 200 cells $/ \mathrm{mm}^{3}$ were found to be significantly associated with fertility desire [6-10]. Unsafe sex among PLHIV has the danger of transmitting HIV to sexual partners and consequently, to children during pregnancy, birth, and breastfeeding. Fertility decisions made by PLHIV and their partners have longterm consequences for the survival and well-being of their families and society in general [11]. The desire and intent to have children among HIV-infected individuals may increase, because of improved quality of life and survival, following the beginning of anti-retroviral treatment and reproductive health services [11]. The relationship between fertility and HIV/AIDS threatens preventive strategies against the HIV epidemic in countries like Ethiopia, where the fertility rate is still high and prevention of mother-tochild transmission (PMTCT) utilization is low [5]. Moreover, unlike the general population, HIV-infected individuals have additional issues to consider, including potential health risks for infections, reproductive health issues, and mother-to-child transmission of HIV $[4,12]$.

In Ethiopia, though studies have been conducted to investigate the fertility desire of people living with HIV/AIDS [12-16], and PMTCT strategy [17] was adopted, fertility desire has given a little of attention, particularly in a pastoral community, in which weak healthcare delivery system is associated with limited PMTCT services [5]. Moreover, there is a limited research on this subject, especially considering health facilities within the Afar region. Therefore, the present study aimed to assess fertility desire and associated factors among HIV-positive women attending ART clinics in the Afar region, Northeast Ethiopia, in order to reduce HIV infections among children born to HIV-positive mothers with a desire to have children.

\section{Material and methods}

\section{Study design and participants}

An institution-based cross-sectional study was conducted among HIV-positive women of the Afar region, Ethiopia, in May 2018. The Afar region is one of nine regions in Ethiopia, and it has a population of 1.8 million. The region has five hospitals: Dubti General Hospital, Aysaita Primary Hospital, Yalo Primary Hospital, and Mohammed Akle General Hospital. The hospitals provide adult and pediatric ART clinics, and voluntary counseling and testing services.

Dubti General Hospital is located in zone one of the Afar region, and $605 \mathrm{~km}$ Northeast of Addis Ababa (the capital city of Ethiopia). According to the hospital administration report of Dubti General Hospital, a total of 2,329 PLHIV were ever enrolled in hospital's ART clinic, and 785 women were on ART during the data collection period. It provides healthcare services for a catchment population of approximately 500,000 people in Semera city administration and adjacent districts.

Mohammed Akle General Hospital is located in zone three of the Afar region, $350 \mathrm{~km}$ Northeast of Addis Ababa, and a total of 1,824 PLHIV were ever enrolled in ART clinic. A total of 527 women were on ART during the data collection period. It provides healthcare services for a catchment population of approximately 250,000 people in zone three and adjacent districts.

\section{Sample size determination and sampling techniques}

Sample size was determined using a single population proportion formula, with the assumption, including 5\% of type one error, $95 \%$ of confidence interval (CI), and 52.9\% of proportion of fertility desire among reproductive-age women in Harare Hospital [14]. Then, we added 5\% to compensate for non-response of participants, and the final sample size was 402 participants, using the following formula:

$$
\mathrm{n}=\frac{(\mathrm{Z} \alpha / 2)^{2} \mathrm{p}(1-\mathrm{p})}{\mathrm{d}^{2}}
$$

where $n$ is required sample size, $Z \alpha / 2$ is critical value for normal distribution at $95 \%$ confidence level (1.96), $p$ is proportion of fertility desire among reproductive age women, and $d$ is 0.05 (5\% margin of error).

Out of the five hospitals in the Afar region, Dubti and Mohammed Akle General Hospital were selected by a simple lottery method, with samples proportionally allocated to each hospital. A systematic random sampling technique was applied to enroll study participants; thus, every three participants were selected using a systematic random sampling technique till the required sample size was reached.

\section{Study variables \\ Dependent variable}

In this study, the dependent variable was 'fertility desire' among reproductive-age women enrolled in ART clinics. Fertility desire is the intention to have children in fertile age between 15 and 49 years [1]. Women who had desire to have children were coded as ' 1 ', while those who did not have the desire were coded as ' 0 ' for logistic regression analysis.

\section{Independent variables}

The independent variables included socio-demographic characteristics (residence, age, religion, marital status, educational status, and community influence), and clinical and reproductive characteristics (previous live-birth, number of children, time since HIV diagnosis, current CD4+ count, partner's HIV status, and disclosure status to partner). 


\section{Data collection tools and techniques}

Data were collected using a pre-tested, structured, and interviewer-administered questionnaire adapted from literature reviews and Ethiopian Demographic and Health Survey [8]. Women were interviewed at the hospitals during their follow-up visits. The questionnaire was first prepared in English and translated into Amharic, and then back to English to validate consistency. Data were collected using Amharic version questionnaire. A tool was pre-tested on 5\% of women in ART clinics other than the selected hospital in Aysaita Primary Hospital. Data were collected by four diploma nurses, and data collectors and supervisors (two BSc nurses) were trained for 2 days by the principal investigator regarding study instrument, objective, consent form, confidentiality, and how to approach study participants.

\section{Data quality control}

Diploma nurses who could speak local language were recruited as data collectors. A pre-tested of the questionnaire was performed on $5 \%$ of the participants before the initiation of the study, which was done to ensure wordings, logical sequence, clarity, and skip patterns of questions. Amendments on the questionnaire were made, and supervisors checked day-to-day activities of data collectors regarding the completion of questionnaires, clarity of responses, and proper coding of answers.

\section{Data management and analysis}

Data were verified and recorded for completeness, coding, and entered into an Epi Data version 3.1 software, and exported to SPSS version 20 for analysis. Descriptive analysis was done, and the results were presented using texts, frequency tables, and mean with standard deviation.

A binary logistic regression analysis was performed to assess the association between the outcome variable with each explanatory variable. Socio-demographic characteristics (residence, age, religion, marital status, educational status, community pressure), and reproductive and health services characteristics (previous live-birth number of children, time since HIV diagnosis, current CD4+ count, partner's HIV status, and disclosure status to partner) were the explanatory variables included in the binary analysis. Therefore, independent variables with a $p$-value less than 0.25 were considered in the final model. Correlation between independent variables was assessed; however, no correlation was found between independent variables. Model fitness was also examined, using Hosmer-Lemeshow model fitness test. Finally, multivariable logistic regression analysis was done to control potential confounders, and to identify factors associated with fertility desire among reproductive-age women on ART. A statistical significance level was established as a $p$-value of less than 0.05 .

\section{Ethical consideration}

The study was approved by ethical review committee (ERC) of the Samara University on February 15, 2018 (No. RE ERC 0018/ 2018). An official letter was written to Afar Regional Health Bureau. Then, permission and support letter was written to Dubti and Mohammed Akle General Hospitals. The individuals enrolled in the study were informed about study objectives, expected outcomes, benefits, and risks related to their participation. A signed written informed consent was acquired from every participant before the interview. Illiterate women consented with their thumbprint. Confidentiality of responses was maintained throughout the study.

\section{Results}

\section{Socio-demographic characteristics}

In this study, a total of 391 women were included, with a response rate of $97.3 \%$. The mean age of the participants was 29.7 years (standard deviation, \pm 7.56 ) and about 168 (74.5\%) women were within 25-34 years age group. In this study, 285 (72.9\%) women were urban residents, 242 (61.9\%) were Muslim, and 281 (71.9\%) were married (Table 1).

\section{Reproductive and clinical characteristics}

In total, 250 (63.9\%) women desired future pregnancy, 216 (55.2\%) had 1-2 living children, 163 (41.7\%) were using contraceptives, and 246 (87.5\%) have disclosed serostatus to their partners. In this study, 197 (50.4\%) partners of the included women showed fertility desire, and 57 (14.76\%) women were currently pregnant (Table 2).

\section{Factors affecting fertility desire among HIV-positive women}

Binary logistic regression analysis showed that young age, not having living child, having 1 or 2 children alive, disclosing serostatus to partner, and contraceptives use, were statistically associated with fertility desire, with $p$-value $<0.05$ (Table 3 ). In multivariable logistic regression analysis, young age, not having alive child, having 1 or 2 living children, and disclosing serostatus to partner, were statistically associated with fertility desire, with $\mathrm{p}<0.05$. On the other hand, the use of contraceptives was associated with decreased odds of fertility desire (Table 3).

In this study, the odds of fertility desire among young age women of 15-24 and 25-34 years were 11.97 (AOR = 11.98; 95\% CI: 4.04-35.5) and 2.93 (AOR $=2.93$; 95\% CI: 1.46-5.86) times more likely compared to age $>34$ years, respectively. Women who did not have living children and women with 1 or 2 children alive were $5.1(\mathrm{AOR}=5.1 ; 95 \% \mathrm{CI}$ : $1.31-20.2)$ and $2.7(\mathrm{AOR}=2.7 ; 95 \% \mathrm{CI}: 1.39-5.27)$ more likely to express fertility desire than women who had more than two children, respectively. The odds of fertility desire among HIV-positive 
Table 1. Socio-demographic characteristics of HIV-positive women attending ART clinics in Afar region, Northeast Ethiopia, May 2018

\begin{tabular}{|c|c|}
\hline Variables & $n(\%)$ \\
\hline \multicolumn{2}{|l|}{ Age } \\
\hline $15-24$ & $101(25.6)$ \\
\hline $25-34$ & $168(43.1)$ \\
\hline$>34$ & $122(31.3)$ \\
\hline Mean age $( \pm \mathrm{SD})$ & Mean age, 29.75 \\
\hline \multicolumn{2}{|l|}{ Residence } \\
\hline Urban & $285(72.9)$ \\
\hline Rural & $106(27.1)$ \\
\hline \multicolumn{2}{|l|}{ Religion } \\
\hline Muslim & $242(61.9)$ \\
\hline Orthodox & $118(30.2)$ \\
\hline Protestant & $31(7.9)$ \\
\hline \multicolumn{2}{|l|}{ Educational status } \\
\hline No education & $94(24.0)$ \\
\hline Primary & $87(22.3)$ \\
\hline Secondary & $168(43.0)$ \\
\hline Higher & $42(10.7)$ \\
\hline \multicolumn{2}{|l|}{ Marital status } \\
\hline Married & $281(71.9)$ \\
\hline Single & $54(13.8)$ \\
\hline Widowed & $21(5.3)$ \\
\hline Divorced & $35(9.0)$ \\
\hline \multicolumn{2}{|c|}{ Community influence to have children } \\
\hline Yes & $285(72.9)$ \\
\hline No & $106(27.1)$ \\
\hline
\end{tabular}

women who disclosed serostatus to their partners were nearly six-fold higher compared to their counterparts (AOR = 5.89; 95\% CI: 2.33-14.9). Women who used contraceptives were $89 \%$ less likely to desire to give birth than their counterparts $(\mathrm{AOR}=0.11 ; 95 \% \mathrm{CI}: 0.05-0.22)$ (Table 3).

\section{Discussion}

This study aimed to determine the fertility desire and associated factors among HIV-positive women attending ART clinics. The prevalence of fertility desire was $63.9 \%$ (95\% CI: 59.1-68.8). Furthermore, multivariable logistic regression analysis revealed that young age, not having living child, having 1 or 2 children alive, and disclosed serostatus to partner, were statistically associated with fertility desire. In contrast, the use of contraceptives was associated with decreased odds of fertility desire.

In this study, the fertility desire among HIV-positive women attending ART clinics was $63.9 \%$ (95\% CI: 59.1-68.8). The study finding was higher than studies performed in
Table 2. Reproductive and clinical characteristics of HIVpositive women attending ART clinics in Afar region, Northeast Ethiopia, May 2108

\begin{tabular}{|c|c|}
\hline Variables & $n(\%)$ \\
\hline \multicolumn{2}{|c|}{ Number of live children } \\
\hline 0 & $55(14.1)$ \\
\hline $1-2$ & $216(55.2)$ \\
\hline$>2$ & $120(30.7)$ \\
\hline \multicolumn{2}{|c|}{ Desire future pregnancy } \\
\hline Yes & $250(63.9)$ \\
\hline No & $141(36.1)$ \\
\hline \multicolumn{2}{|c|}{ Use of contraceptives } \\
\hline Yes & $163(41.7)$ \\
\hline No & $228(58.3)$ \\
\hline \multicolumn{2}{|c|}{ Sexual intercourse in the last six months } \\
\hline Yes & $295(75.4)$ \\
\hline No & $96(24.6)$ \\
\hline \multicolumn{2}{|l|}{ CD4+ count } \\
\hline$\leq 200$ & $49(12.5)$ \\
\hline 201-499 & $117(29.9)$ \\
\hline$\geq 500$ & $225(57.6)$ \\
\hline \multicolumn{2}{|c|}{ Partner tested for HIV } \\
\hline Yes & $253(64.7)$ \\
\hline No & $19(4.9)$ \\
\hline I do not know & $9(2.3)$ \\
\hline \multicolumn{2}{|c|}{ Partner HIV test result } \\
\hline Positive & $224(88.5)$ \\
\hline Negative & 29 (11.5) \\
\hline \multicolumn{2}{|c|}{ Disclose sero status to partner } \\
\hline Yes & $246(87.5)$ \\
\hline No & $35(12.5)$ \\
\hline \multicolumn{2}{|c|}{ Partner fertility desire } \\
\hline Yes & $197(50.4)$ \\
\hline No & $84(21.5)$ \\
\hline \multicolumn{2}{|l|}{ Currently pregnant } \\
\hline Yes & $57(14.6)$ \\
\hline No & $334(85.4)$ \\
\hline
\end{tabular}

Tigray region (45\%) [12], Uganda (57.1\%) [18], Malawi (45\%) [19], and Harare regional state (52.9\%) [14]. This may be due to differences in socio-demographic characteristics of the populations, cultural disparities on having large family size, and fertility rate. Moreover, the difference might be the level of difference in health services provision or awareness, particularly about prevention of mother-to-child transmission (PMTCT) across the study settings. It was noted that there were previous efforts to discourage childbearing among PLWHA in most countries $[1,3]$. 
Table 3. Binary and multivariable logistic regression on factors that affect fertility desire among HIV-positive women attending ART clinics in Afar region, Northeast Ethiopia, May 2108

\begin{tabular}{|c|c|c|c|c|}
\hline \multirow[t]{2}{*}{ Variables } & \multicolumn{2}{|c|}{ Fertility desire } & \multirow[t]{2}{*}{ COR $(95 \% \mathrm{Cl})$} & \multirow[t]{2}{*}{ AOR $(95 \% \mathrm{Cl})$} \\
\hline & Yes, $n(\%)$ & No, $n(\%)$ & & \\
\hline \multicolumn{5}{|l|}{ Age } \\
\hline $15-24$ & $80(32.0)$ & $21(14.9)$ & $3.81(2.10-6.90)^{*}$ & $11.98(4.04-35.50)^{*}$ \\
\hline $25-34$ & $109(43.6)$ & $59(41.8)$ & $1.85(1.15-2.97)$ & $2.93(1.46-5.86)^{*}$ \\
\hline$>34$ & $61(24.4)$ & $61(43.3)$ & 1.00 & 1.00 \\
\hline \multicolumn{5}{|c|}{ Children alive } \\
\hline 0 & $40(10.6)$ & $15(16.0)$ & $2.76(1.30-5.76)^{*}$ & $5.1(1.31-20.20)^{\star}$ \\
\hline $1-2$ & $149(59.6)$ & $67(47.4)$ & $2.21(1.39-3.50)^{*}$ & $2.7(1.39-5.27)^{\star}$ \\
\hline$>2$ & $61(24.4)$ & $59(41.8)$ & 1.00 & 1.00 \\
\hline \multicolumn{5}{|c|}{ Use of contraceptives } \\
\hline Yes & $82(32.8)$ & $81(57.4)$ & $0.36(0.24-0.50)^{*}$ & $0.11(0.05-0.22)^{*}$ \\
\hline No & $168(67.2)$ & $60(42.6)$ & 1.00 & 1.00 \\
\hline \multicolumn{5}{|c|}{ Disclose HIV status to partner } \\
\hline Yes & $178(94.7)$ & $68(73.1)$ & $6.50(2.90-14.30)^{\star}$ & $5.89(2.33-14.9)^{\star}$ \\
\hline No & $10(5.3)$ & $25(26.9)$ & 1.00 & 1.00 \\
\hline
\end{tabular}

In this study, the odds of fertility desire among young ages women of 15-24 and 25-34 years were 11.97 and 2.93 times more likely compared to age $>34$ years, respectively. This finding is in line with studies performed in Ethiopia, Uganda, and Brazil $[10,20,21]$, and might be related to the fact that older women living with HIV have already achieved their desire family size compared to their younger counterparts.

The number of surviving children was a predictor of fertility desires among HIV-positive women attending ART clinics. Women who were not having living children and those having 1 or 2 children alive were 5.1 and 2.7 times more likely to desire more children than women with more than two children, respectively. This result was similar to that of studies done in Harare region, Addis Ababa, Oromia region, Malawi, and Nigeria $[10,14,15,19]$. This might be because HIV-positive women, like anyone else, could have the desire to have children until they achieve their preferred family size. Moreover, the access to anti-retroviral therapy has improved their quality of life, allowing for leading healthier and more productive lives as well as improved the survival of HIV-infected people; hence, they would anticipate childbearing $[1,10,22]$. Furthermore, studies suggested that PLWHA desire and continue to have children equally as those without HIV infection $[1,23]$.

The odds of fertility desire among HIV-positive women who disclosed serostatus to their partners were nearly six-fold higher compared to their counterparts, which is in line with studies done in Ethiopia, Uganda, and Tanzania [6, 9, 24]. This might be the fact that those who disclosed their status could have more discussion on their desired number of children, and that HIV-positive women may want to have children to ensure family continuity and having descendants of their own children to inherit their name, and to be supported in old age. It has been noted that disclosing serostatus to their partners helped in better communication between partners, and could play an important role in pre-conception planning behaviors [12].

In this study, women who used contraceptives were $89 \%$ less likely to express fertility desires than their counterpart, which is in line with studies performed in Harare regional state, Ethiopia, and Papua New Guinea [14, 25]. This might be the fact that contraceptive use is significant for HIV-positive patients to limit births and prevent unplanned pregnancy, and at the same time, reduce HIV-positive births irrespective of their fertility desire and optimization of the number of children.

\section{Limitation}

This study was an institution-based study and cannot be generalized to the general population in the community. Cause and effect relation is not guaranteed because of cross-section study design. Moreover, reported behaviors, particularly those associated with sexual life, may be affected by desirability bias. Finally, the study was not supplemented with qualitative methods, since the focused group discussion or other qualitative methods increased the risk of ethical confidentiality.

\section{Conclusions}

This study showed that six in ten HIV-positive women attending ART clinics presented fertility desire. Young 
age, not having living child, having 1 or 2 children alive, disclosed serostatus to partner, and contraceptive use were the predictors of fertility desire. Therefore, counseling services for younger women living with HIV are needed to provide the knowledge on how to prevent mother-to-child transmission in their pursuit to have children, not just consider expressing their fertility desires.

\section{Acknowledgments}

We would like to thank the Samara University and Afar Regional Health Bureau for providing ethical and permission letters. We would also like to acknowledge the study subjects, data collectors, and supervisors.

\section{Conflict of interest}

The authors have no conflict of interest.

\section{Reference}

1. Siegfried N, van der Merwe L, Brocklehurst P, Sint TT. Antiretrovirals for reducing the risk of mother-to-child transmission of HIV infection. Cochrane Database Syst Rev 2011; 7: CD003510.

2. Kagaayi J, Serwadda D. The history of the HIV/AIDS epidemic in Africa. Curr HIV/AIDS Rep 2016; 13: 187-193.

3. World Health Organization. Global health sector strategy on HIV 2016-2021. Towards ending AIDS. Geneva: World Health Organization; 2016.

4. Nansseu JRN, Bigna JJR. Antiretroviral therapy-related adverse effects: can sub-Saharan Africa cope with the new "test and treat" policy of the World Health Organization? Infect Dis Poverty 2017; 6: 24 .

5. Central Statistical Agency. Ethiopia Demographic and Health Survey 2016. Addis Ababa: Central Statistical Agency 2017.

6. Alemayehu B, Aregay A. Desire to procreate among people living with HIV/AIDS: determinants in Ethiopia: a cross-sectional study. J AIDS HIV Res 2012; 4: 128-135.

7. Asfaw HM, Gashe FE. Fertility intentions among HIV positive women aged 18-49 years in Addis Ababa Ethiopia: a cross-sectional study. Reprod Health 2014. DOI: https://doi.org/10.1186/1742-475511-36.

8. Loutfy MR, Hart TA, Mohammed SS, et al. Fertility desires and intentions of HIV-positive women of reproductive age in Ontario, Canada: a cross-sectional study. PLoS One 2009; 4: e7925.

9. Mmbaga EJ, Leyna GH, Ezekiel MJ, Kakoko DC. Fertility desire and intention of people living with HIV/AIDS in Tanzania: a call for restructuring care and treatment services. BMC Public Health 2013. DOI: https://doi.org/10.1186/1471-2458-13-86.

10. Negash S, Yusuf L, Tefera M. Fertility desires predictors among people living with HIV/AIDS at art care centers of two teaching hospitals in Addis Ababa. Ethiop Med J 2013; 51: 1-11.

11. Kumar S. Preventing mother to child transmission of HIV - current strategies. Med J Armed Forces India 2014; 70: 307-308.

12. Melaku YA, Zeleke EG, Kinsman J, Abraha AK. Fertility desire among HIV-positive women in Tigray region, Ethiopia: implications for the provision of reproductive health and prevention of mother-to-child HIV transmission services. BMC Womens Health 2014; 14: 137.

13. Getachew M, Alemseged F, Abera M, Deribew A. Factors affecting fertility decisions of married men and women living with HIV in South Wollo Zone, Northeast Ethiopia. Ethiopian Journal of Health Development 2010; 24. DOI: 10.4314/ejhd.v24i3.68388.
14. Haile F, Isahak N, Dessie A. Fertility desire and associated factors among people living with HIV on ART, in Harari Regional State, Eastern Ethiopia. J Trop Dis 2014; 2: 137. DOI: 0.4172/2329-891X. 1000137.

15. Kaoje A, Ibrahim M, Njoku C, Gusau G, Saad A, Raji M. Predictors of fertility desire among people living with HIV attending the anti-retroviral clinic in a tertiary health facility in Sokoto, Northern Nigeria. Sahel Medical Journal 2015; $18: 14$.

16. Tesfaye L, Admassu M, Getachew A, Sharma HR. Fertility desires and family planning demand among HIV-positive clients in follow-up care at an antiretroviral treatment unit in Gondar university hospital, Ethiopia. Vulnerable Children and Youth Studies 2012; 7: 20-35.

17. Federal Ministry of Health. Guidelines for Prevention of Motherto-Child Transmission of HIV in Ethiopia. Federal HIV/AIDS Prevention and Control Office; Federal Ministry of Health; 2007.

18. Matovu JK, Makumbi F, Wanyenze RK, Serwadda D. Determinants of fertility desire among married or cohabiting individuals in Rakai, Uganda: a cross-sectional study. Reprod Health 2017. DOI: 10.1186/ s12978-016-0272-3.

19. Krashin JW, Haddad LB, Tweya H, et al. Factors associated with desired fertility among HIV-positive women and men attending two urban clinics in Lilongwe, Malawi. PLoS One 2018; 13: e0198798.

20. King R, Khana K, Nakayiwa S, et al. 'Pregnancy comes accidentallylike it did with me': reproductive decisions among women on ART and their partners in rural Uganda. BMC Public Health 2011; 11: 530 .

21. Nóbrega AA, Oliveira FA, Galvão MT, et al. Desire for a child among women living with HIV/AIDS in northeast Brazil. AIDS Patient Care STDS 2007; 21: 261-267.

22. Kawale P, Mindry D, Stramotas S, et al. Factors associated with the desire for children among HIV-infected women and men: a quantitative and qualitative analysis from Malawi and implications for the delivery of safer conception counseling. AIDS Care 2014; 26 : 769-776.

23. Ogilvie GS, Palepu A, Remple VP, et al. Fertility intentions of women of reproductive age living with HIV in British Columbia, Canada. LWW; 2007.

24. Kakaire O, Osinde MO, Kaye DK. Factors that predict fertility desires for people living with HIV infection at a support and treatment center in Kabale, Uganda. Reprod Health 2010; 7: 27.

25. Aska ML, Chompikul J, Keiwkarnka B. Determinants of fertility desires among HIV positive women living in the Western Highlands province of Papua New Guinea. World Journal of AIDS 2011; 1 : 198-207. 